Georgia State University

ScholarWorks @ Georgia State University

\title{
Neural circuitry engaged during unsuccessful motor inhibition in pediatric bipolar disorder
}

\author{
Ellen Leibenluft \\ National Institutes of Health \\ Brendan A. Rich \\ National Institutes of Health \\ Deborah T. Vinton \\ National Institutes of Health \\ Eric E. Nelson \\ National Institutes of Health \\ Stephen J. Fromm \\ National Institutes of Health, stephen.fromm@nih.gov
}

See next page for additional authors

Follow this and additional works at: https://scholarworks.gsu.edu/psych_facpub

Part of the Psychology Commons

\section{Recommended Citation \\ Leibenluft, Ellen; Rich, Brendan A.; Vinton, Deborah T.; Nelson, Eric E.; Fromm, Stephen J.; Berghorst, Lisa H.; Joshi, Paramijit; Robb, Adelaide; Schachar, Russell J.; Dickstein, Daniel P.; Tone, Erin; and Pine, Daniel S., "Neural circuitry engaged during unsuccessful motor inhibition in pediatric bipolar disorder" (2007). Psychology Faculty Publications. 141. \\ https://scholarworks.gsu.edu/psych_facpub/141}

This Article is brought to you for free and open access by the Department of Psychology at ScholarWorks @ Georgia State University. It has been accepted for inclusion in Psychology Faculty Publications by an authorized administrator of ScholarWorks @ Georgia State University. For more information, please contact scholarworks@gsu.edu. 


\section{Authors}

Ellen Leibenluft, Brendan A. Rich, Deborah T. Vinton, Eric E. Nelson, Stephen J. Fromm, Lisa H. Berghorst, Paramijit Joshi, Adelaide Robb, Russell J. Schachar, Daniel P. Dickstein, Erin Tone, and Daniel S. Pine 


\title{
Neural circuitry engaged during unsuccessful motor
}

\section{inhibition in pediatric bipolar disorder}

\author{
Ellen Leibenluft, Brendan A. Rich, Deborah T. Vinton, Eric E. Nelson, Stephen J. \\ Fromm, Lisa H. Berghorst, Paramjit Joshi*, Adelaide Robb*, Russell J. Schachar**, \\ Daniel P. Dickstein, Erin B. McClure, Daniel S. Pine
}

Mood \& Anxiety Disorders Program, National Institute of Mental Health, Bethesda, MD *Children's National Medical Center, Washington, D.C.

**Department of Psychiatry, University of Toronto and Research Institute, The Hospital for Sick Children, Toronto, Canada

Keywords: Pediatric Bipolar Disorder, fMRI, Motor Inhibition, Striatum

Article Statistics:

Article: 4,747 words

Abstract: 245 words

Figures: 2

Tables: 4

\section{Corresponding Author:}

Ellen Leibenluft

National Institute of Mental Health

Pediatrics and Developmental Neuropsychiatry Branch

10 Center Drive MSC 1255

Building 10, Room 4N208

Bethesda, MD 20892

Tel: 301-496-5323

Fax: 301-402-8497

Leibs@mail.nih.gov 
Objective: Deficits in motor inhibition may contribute to impulsivity and irritability in children with bipolar disorder (BPD). Therefore, studies of the neural circuitry engaged during failed motor inhibition in pediatric BPD may contribute to our understanding of the pathophysiology of the illness. We tested the hypothesis that children with BPD and controls would differ in ventral prefrontal cortex (vPFC), striatal, and anterior cingulate activation during unsuccessful motor inhibition. We also compared activation in medicated vs. unmedicated children with BPD, and in children with BPD and ADHD (BPD+ADHD) vs. those with BPD but without ADHD (BPD-ADHD).

Method: Event-related fMRI study comparing neural activation in children with BPD and controls while they performed a motor inhibition task. The sample included 26 children with BPD (13 unmedicated, 15 with ADHD) and 17 age, gender, and IQ matched controls.

Results: On failed inhibitory trials, controls showed greater bilateral striatal and right vPFC activation than did patients. While our findings were somewhat more prominent in unmedicated than medicated, patients, and in BPD+ADHD than BPD-ADHD, the findings did not differ significantly (?) among these subgroups of children with BPD.

Conclusions: Compared to controls, children with BPD may have deficits in their ability to engage striatal structures and right vPFC during unsuccessful inhibition. (this reads confusingly to me- -they're deficient in their capacity to engage structures when they're behaviorally unsuccessful? Perhaps reword?) Further research is needed to determine whether these deficits play a role in the emotional and behavioral dysregulation characteristic of BPD. 


\section{$\underline{\text { Introduction }}$}

Deficits in motor inhibition might produce symptoms of impulsivity and affective aggression in pediatric $\operatorname{BPD}(1,2)$ while also contributing to diagnostic confusion between attention deficit hyperactivity disorder (ADHD) and BPD (3). The neural circuitry engaged during unsuccessful motor inhibition in pediatric bipolar disorder (BPD) is therefore of interest. Research on the pathophysiology of these shared motor symptoms could identify common and distinct neural mechanisms between ADHD and BPD. Finally, motor inhibition is mediated by the ventral prefrontal cortex (vPFC), striatum, and anterior cingulate, areas implicated in the pathophysiology of BPD (4-12).

The current study selected regions of interest (ROIs) based on studies implicating common brain regions in BPD and motor inhibition. fMRI studies in adult BPD found patientcontrol differences in vPFC activation during various tasks $(13,14)(15,16)$. One study in children with both BPD and a family history of the illness found that, compared to controls, patients had increased vPFC activation while viewing emotional pictures or performing a spatial working memory task(17). In the same study, children with BPD had greater anterior cingulate activation than controls during the spatial working memory task, consistent with fMRI $(18,19)$ studies in bipolar adults. With regard to the striatum, four studies in BPD (two of adults, two of youth) reported increased activation in patients vs. controls.

We studied vPFC, striatal, and cingulate activation in children with BPD who performed an event-related version of the stop signal task, a motor inhibition paradigm used to study ADHD (20). Because the failure to appropriately inhibit a motor response is an important symptom in pediatric BPD, we were particularly interested in circuitry engaged during unsuccessful motor inhibition. The stop signal paradigm includes two features that 
facilitate the study of such circuitry. First, the paradigm adjusts difficulty based on subject performance, so that all subjects fail to inhibit on approximately $50 \%$ of inhibitory trials. This ensures a relatively large number of unsuccessful inhibitory (“stop incorrect”) trials to contrast with both successful inhibitory (“stop correct”) trials and go trials. Second, all trials begin with a go signal, followed in approximately $25 \%$ of trials, by a stop signal. Thus, the contrast of "stop incorrect" vs. "go" trials controls for the presence of both a motor response and a go signal, thus isolating circuitry engaged during failed motor inhibition. In addition, the "stop correct” vs. "stop incorrect” contrast examines the circuitry engaged during successful inhibition. This contrast controls for stimulus properties (i.e. the presence of both go and stop signals), but not for the presence or absence of a motor response.

In research in this area, two potential confounds deserve particular attention: medication and comorbid ADHD. We recruited enough children with BPD to compare neural activation in medicated vs. unmedicated patients, and in those with vs. without ADHD. Such comparisons are rare in the literature. One fMRI study of adult bipolar patients compares unmedicated to medicated patients (REF Caliguiri). All other published fMRI studies in BPD include predominantly medicated subjects (NEED REFS). Similarly, while studies find comorbid ADHD in at least 60\% of children with BPD (REF), previous fMRI studies have not compared activation in bipolar children with and without comorbid ADHD.

We used rapid event-related fMRI and the stop signal task to study motor inhibition in children with BPD. Given the clinical importance of failed motor inhibition in pediatric BPD, we focused on circuitry engaged during unsuccessful inhibition. Because the vPFC, anterior cingulate, and striatum have been implicated in both motor inhibition and BPD, we hypothesized that patients and controls would differ in activation in these regions. In addition, 
we compared activation in medicated patients vs. unmedicated patients, and in bipolar patients with ADHD (BPD+ADHD) vs. those without ADHD (BPD-ADHD).

\section{Methods}

Subjects

The patient group consisted of $\mathbf{X X}$ youth recruited via advertisements to patient advocacy groups. All patients met DSM-IV diagnostic criteria for BPD and exhibited the narrow phenotype of BPD, in that each had a history of at least one hypomanic or manic episode meeting full duration criteria and including expansive, elevated mood(3). Patients were excluded if they had severe Pervasive Developmental Disorder, substance use within the past 3 months, or IQ $<70$. A best-estimate diagnostic approach was used, as described elsewhere (give ref), integrating data from the Schedule for Affective Disorders and Schizophrenia (K-SADS-PL(21); parent and child were interviewed separately by clinicians, master's level or above, with kappa $\geq 0.9$ ), treating physicians, and medical records. Comorbid diagnoses were assigned only if the patient met criteria for the comorbid diagnosis while euthymic. Thus, the diagnosis of comorbid ADHD could not be due to the overlap between symptoms of ADHD and those of mania or hypomania.

Of the XX patients scanned, data from 26 were usable. A priori exclusion criteria included inadequate task performance (i.e., < 65\% correct on go trials) or excessive movement (> $2.5 \mathrm{~mm}$ in any plane). Data were not usable for YY patients, and the clinical data provided below includes only the 26 patients with usable scanning data.

Comorbid disorders were common (Table 1). Fifteen patients (58\%) had a comorbid diagnosis of ADHD. Clinicians completed mood ratings (Young Mania Rating Scale 
(YMRS)(22) and Children's Depression Rating Scale (CDRS)(23)) within 24 hours of scanning (Table 1). Five patients were hypomanic (YMRS score $>12$ but $<=20$ ) and the remaining 21 were euthymic. Thirteen patients (50\%) were medicated (for medication types, see Table 1).

Controls comprised 26 youth with no K-SADS-PL(24) diagnosis, no DSM-IV diagnoses in first-degree relatives (family history was ascertained by parent interview), no use of psychoactive substances, and IQ>70. Of the 26 scanned controls, data from 17 were usable.

Groups did not differ significantly on age, gender, or IQ(25) (Table 1). The study was approved by the NIMH IRB; participants and a parent provided written informed consent/assent.

\section{Behavioral Task}

The task was based on previously published work $(26,27)$. On all trials, a white fixation cross appeared for $500 \mathrm{~ms}$; it was replaced by an "X" or "O" "go-signal” for $1000 \mathrm{~ms}$ (Fig.1). Using a button-box, subjects pressed " 1 " for "X" and "2" for "O". Subjects were told to respond within $1000 \mathrm{~ms}$, unless the background changed to red, which occurred on $25 \%$ of the trials (i.e. stop trials). In these instances, they were instructed not to press either button.

On the first stop trial, the stop signal appeared $250 \mathrm{~ms}$ after the go-signal. Subsequent stop-signal timing was based on subject performance. If the subject successfully inhibited, the next stop signal appeared $50 \mathrm{~ms}$ later, making inhibition more difficult; if the subject failed to inhibit, the signal appeared 50 ms earlier, making inhibition easier. Trials were separated by $750 \mathrm{~ms}$.

Prior to scanning, subjects were trained to achieve a mean reaction time (RT) less than 1000 msec on "go" trials and successful inhibition on $40-60 \%$ of stop trials. Subjects received 
feedback after each block during scanning; they were told to decrease their reaction time if the mean exceeded 1000 ms.

\section{Scanning acquisition}

Scanning occurred in a GE Signa 3Tesla magnet at NIMH. Head movement was restricted with padding; images were presented via Avotec Silent Vision Glasses (Stuart, FL). Gradient echo planar images (EPI) were acquired after sagittal localization and manual shimming. EPI images used 23 contiguous 5mm axial slices, parallel to the AC-PC line, and EPI single-shot gradient echo T2* weighting (matrix 64x64; TR =2000 ms; TE =40 ms; Field of View $=240 \mathrm{~mm}$; voxels $3.75 \times 3.75 \times 5 \mathrm{~mm}$ ).

Subjects completed four runs, each with 32 go, 16 stop, and 16 blank fixation trials distributed randomly throughout each block. Blank fixation trials were included, based on the "rapid-event-related" paradigm of Holmes and Friston (REF), and Zarahn (REF), to allow deconvolution of unique events occurring close in time. These trials provide an implicit statistical baseline (REF Zarahn).

A high resolution T1 weighted anatomical image was acquired for spatial normalization. A standardized magnetization prepared gradient echo sequence was used (180 $1 \mathrm{~mm}$ sagittal slices; FOV $=256 ; \mathrm{NEX}=1 ; \mathrm{TR}=11.4 \mathrm{~ms} ; \mathrm{TE}=4.4 \mathrm{~ms}$, matrix $=256 \times 256 ; \mathrm{TI}$ $=300 \mathrm{~ms} ;$ bandwidth = $130 \mathrm{~Hz} /$ pixel, 33kHz/256 pixels). 


\section{Data Analysis}

$\underline{\text { Behavioral data }}$

The following were recorded during scanning: RT and accuracy on go trials (GoRT), accuracy on stop trials, and inhibit delay (i.e. interval between the onsets of the go and stop signals). The stop signal reaction time (SSRT), or speed of inhibition, was calculated. When a subject inhibits successfully on $50 \%$ of stop trials, the SSRT is the mean GoRT minus the mean inhibit delay $(27,28)$. Since subjects' accuracy on stop trials may deviate from $50 \%$, an interpolation algorithm was used to calculate SSRT: the mean stop signal delay was subtracted from the GoRT at the $\mathrm{x}^{\text {th }}$ percentile, where $\mathrm{x}$ is the subject's \% accuracy on stop trials.

\section{Imaging data}

Primary analyses

Analyses were conducted with SPM99b. Preprocessing included slice time correction, motion correction, and spatial normalization. At the subject level, event-related response amplitudes were estimated using the General Linear Model (GLM). Event types included unsuccessful stop (“stop-incorrect”), “correct-go” (“go”; N.B. hereinafter, “go” refers only to correct go trials), and successful-stop (“stop-correct”) trials. A rectangular pulse (2250 msec, the length of each event) was used to model each event, convolved with the hemodynamic response function provided by SPM. A high pass filter of .024 Hz was applied.

Contrast images were created for each subject using pairwise comparisons of eventrelated response amplitudes. The primary analysis was activation on stop-incorrect vs. go trials, in BPD vs. controls. We also compared activation on stop-correct vs. stop-incorrect trials, in BPD vs. controls. For both contrasts, subsequent analyses compared medicated 
patients to controls, unmedicated patients to controls, and unmedicated to medicated patients. In addition we compared BPD+ADHD to controls, BPD-ADHD to controls, and BPD+ADHD to BPD-ADHD on both contrasts.

Prior to group analysis, each contrast image was proportionally scaled. These normalized contrast images were smoothed using an isotropic Gaussian kernel (FWHM = 11.4 mm). A group level random effects model was employed to provide population levelinference.

A small volume corrected, ROI analysis was used: the ROIs were bilateral vPFC, striatum (accumbens, caudate, putamen), and anterior cingulate. Significance was set at $\mathrm{p}<.05$. ROI templates were defined on the canonical single subject's structural MRI images supplied by SPM99. Templates were defined using MedEx software, drawn by hand in the coronal plane, and applied to all normalized brains at the group level. Coordinates are in Montreal Neurological Institute (MNI) space. The cingulate, putamen, and caudate were ascertained from standard anatomical criteria.(29-32). The accumbens was identified at the inferior junction between the head of the caudate and putamen. It was delimited superiorly by a line connecting the inferior corner of the lateral ventricle and the inferior point of the internal capsule abutting the accumbens, and laterally by a vertical line passing from the latter point(33). The vPFC boundaries were defined as the last slice with the anterior horizontal ramus, the last slice containing the olfactory sulcus, anterior horizontal ramus, and the olfactory sulcus (Monk, 2003; McClure Bio Psych gender paper, 2004).

\section{$\underline{\text { Results }}$}

\section{$\underline{\text { Behavioral Data }}$}


There were no between-group differences in mean inhibit delay, go RT, stop accuracy, or SSRT, but patients had significantly lower go accuracy than controls (Table 2). In the fMRI analysis, to control for between-group differences in stop and go accuracy, only correct go trials were used; stop-correct and stop-incorrect trials were analyzed separately. There were no significant behavioral differences between unmedicated and medicated patients, or between BPD+ADHD vs. BPD-ADHD.

\section{Imaging data}

\section{Stop incorrect vs. go}

All bipolar patients vs. controls: Bipolar patients did not show increased activation relative to controls in any ROI. However, controls had greater activation than patients in caudate, putamen, accumbens, and vPFC (Table 3).

Effect of medication: There were no significant differences between unmedicated and medicated patients in any ROI. The comparisons of controls vs. medicated patients, and of controls vs. unmedicated patients, yielded similar results. That is, controls had greater activation than unmedicated patients in accumbens, caudate, and putamen, with a trend toward increased activation in vPFC (Table 3). Similarly, controls had greater activation than medicated patients in left accumbens, left caudate, and right vPFC, with a trend toward greater activation in right accumbens (Table 3).

Effect of comorbid ADHD: There were no significant differences between BPD+ADHD and BPD-ADHD in any ROI. Controls had greater activation than did BPD+ADHD in striatum (bilateral accumbens, caudate, and putamen), as well as bilateral anterior cingulate and vPFC (Table 3). The differences between controls and BPD-ADHD were limited to the striatum, 
with controls having greater activation in bilateral accumbens and left caudate, with a trend toward greater activation in left putamen (Table 3).

\section{Stop correct vs. stop incorrect}

All bipolar patients vs. controls: With all bipolar patients included in the analysis, patients had increased activation compared to controls in the right vPFC (Table 3). Patients and controls did not differ on any other ROI.

Effect of medication: ,There were no significant differences between medicated patients and controls in any ROI. However, unmedicated patients had significantly greater activation than controls in bilateral accumbens, caudate, and putamen, in right OFC, and in right anterior cingulate (Table 4). Similarly, unmedicated patients had significantly greater activation than did medicated patients in bilateral accumbens, left putamen, and right caudate (Table 4).

Effect of comorbid ADHD: , There were no significant differences between BPDADHD and controls in any ROI. However, BPD+ADHD had greater activation than controls in right accumbens, right putamen, and right vPFC (Table 4). BPD+ADHD also had greater activation than BPD-ADHD in bilateral accumbens, putamen, and vPFC, and left caudate (Table 4).

\section{Across-condition comparison at peak voxels}

These results indicate greater striatal and right vPFC activation in controls than patients in the stop incorrect vs. go contrast, and greater striatal and right vPFC activation in patients than controls in the stop correct vs. stop incorrect contrast. These findings could both be due to increased striatal and vPFC activation in controls, compared to patients, on incorrect stop trials. 
To explore this possibility, for the right vPFC and each striatal ROI, we identified the voxel showing the greatest between-group difference in the stop incorrect vs. go contrast. For that voxel, we plotted the mean beta on the stop correct vs. fixation, stop incorrect vs. fixation, and go vs. fixation contrasts. Blank fixation trials were used so that the responses to the other conditions could be estimated efficiently (Friston, Zarahn, Josephs et al, NeuroImage 10, 607 - 619, 1999). This yielded a series of histograms, one for each striatal area and one for right vPFC. Each histogram showed a similar pattern: i.e., controls showed significantly greater activation than patients on stop incorrect trials (see Fig. X).

\section{$\underline{\text { Discussion }}$}

Given the importance of failed inhibition in the clinical presentation of pediatric BPD, we used rapid event-related fMRI to study the neural circuitry engaged during unsuccessful inhibitory trials. On such trials, controls showed greater bilateral striatal and right ventral prefrontal activation than did patients. While our findings were somewhat more prominent in unmedicated, compared to medicated, patients, and in BPD+ADHD, compared to BPDADHD, the findings did not differ significantly (?) among these subgroups of children with BPD.

Whereas SSRT did not differ between groups in these small samples, data from a larger sample indicate a trend suggesting that bipolar patients may be slower than controls to inhibit prepotent responses (34). Moreover, data from related tasks indicate that children with BPD have deficits in motor regulation (34). Neuroimaging and basic research implicate the striatum in the learning and execution of motor programs (35). Recent research in adults indicates striatal engagement with increasing neurocognitive load (36), and animal research suggests that 
striatal dopaminergic neurons produce error signals(37). (this paragraph doesn’t flowperhaps rewrite the preceding 3 sentences to soften the jump from deficient motor regulation to striatal function) Data presented here and elsewhere(34) suggest that motor inhibition deficits in pediatric BPD may reflect a failure to engage the striatum appropriately during failed inhibition.

Our finding contrasts with four studies showing increased, rather than decreased, striatal activation in patients with BPD vs. controls(38-41). Various factors could account for such inconsistencies. None of the studies finding striatal hyper-activation used a motor inhibition paradigm, although one(42) did employ an interference task. Moreover, we examined neural activation on a trial-by-trial basis in relation to subject behavior unlike prior studies in which behavioral data were not obtained(43, 44), block designs were used(45), or ceiling-effects occurred (46). While the data presented here indicate decreased striatal activation in patients vs. controls during failed inhibition, we have observed increased striatal activation in patients vs. controls in a different psychological context (unpub data); a similar phenomenon has been reported with regard to dorsolateral prefrontal function in patients with schizophrenia (Callicott, AJP 2003). Thus, striatal dysfunction in BPD may manifest differently across different situations.

These results may elucidate how striatal dysfunction contributes to disinhibition and other affective and behavioral impairments in pediatric BPD. Patients with BPD have motor abnormalities in both depressed and manic states i.e., hyperactivity in mania and hypo- or hyperactivity in depression. Also, impulsivity is an important clinical feature of BPD, across mood states and between episodes. In adults with BPD, impulsivity is frequently associated with risky behavior such as substance abuse, present in $60 \%$ of adults with BPD (47). In 
children with BPD, impulsivity is associated with irritability, and both are impairing across mood states (48). Data in control children suggest that irritability and decreased motor inhibition may be related mechanistically: in controls, impaired motor inhibition (i.e., increased SSRT) is associated with increased intensity of experienced anger(49). Speculatively, we suggest that the impulsivity seen in patients with BPD across the developmental spectrum is associated with failure to engage the striatum in situations requiring motor inhibition. If so, interventions that facilitate striatal engagement in such contexts might provide avenues to decrease impulsivity in BPD.

We found between-group differences in the right vPFC that, although less robust and consistent than those in the striatum, followed a similar pattern, in which controls showed greater vPFC activation than patients on failed inhibitory trials. The congruence of our vPFC and striatal findings is consistent with nonhuman primate research indicating significant structural and functional connections between the two regions (REF).

With one exception (Caligiuri), fMRI studies of neither children nor adults with BPD have examined the impact of either medication or comorbid illnesses on neural activation. Using a simple motor task, Caligiuri et al reported increased cortical and subcortical activation in bipolar adults that was normalized by medication. We also found that medication dampened patient-control differences, suggesting that studies of medicated patients might be prone to Type II, rather than Type I, errors. With regard to comorbid ADHD, we found that bipolar children with or without ADHD differed from controls in striatal activation during failed inhibition (i.e., on the stop incorrect vs. go contrast). However, on the stop correct vs. stop incorrect contrast, BPD+ADHD, but not BPD-ADHD, differed from controls, and BPD+ADHD differed from BPD-ADHD in activation on several ROIs. Thus, the impact of 
comorbidity on fMRI results in pediatric BPD can be complex, varying from contrast to contrast and, possibly, with the behavioral paradigm. Finally, it is unclear whether the pathophysiology of ADHD symptoms is the same in children with BPD and children with ADHD only or, alternatively, whether ADHD in children with BPD is a phenocopy of the more common forms of $\mathrm{ADHD}(50)$. Indeed, whereas we found increased right vPFC activation in BPD+ADHD vs. controls on the stop correct vs. stop incorrect contrast, a study in ADHD children found that patients, compared to controls, had significantly reduced activation in the right inferior frontal PFC during successful inhibition (Rubia, AJP, 2005). CHECK THIS Follow-up research should compare fMRI data from children with ADHD only to children with BPD. Also, further study is needed to ascertain the possible impact of mood state on our results. Since 18 of 22 patients were euthymic, the deficits we identified may be trait-related, but more definitive work is needed.

In sum, our data indicate that, compared to controls, children with BPD may have deficits in their ability to engage striatal structures and right vPFC during unsuccessful inihibition. These results may give clues to the pathophysiology of disinhibition and impulsivity in BPD. 


\section{Reference List}

1. Swann, A. C., Dougherty, D. M., Pazzaglia, P. J., Pham, M. \& Moeller, F. G. (2004) Bipolar. Disord. 6, 204-212.

2. Leibenluft, E., Blair, R. J., Charney, D. S. \& Pine, D. S. (2003) Ann. N. Y. Acad. Sci. 1008, 201-218.

3. Leibenluft, E., Charney, D. S., Towbin, K. E., Bhangoo, R. K. \& Pine, D. S. (2003) Am. J. Psychiatry 160, 430-437.

4. Blumberg, H. P., Martin, A., Kaufman, J., Leung, H. C., Skudlarski, P., Lacadie, C., Fulbright, R. K., Gore, J. C., Charney, D. S., Krystal, J. H. et al. (2003) Am. J Psychiatry 160, 1345-1347.

5. Aron, A. R., Fletcher, P. C., Bullmore, E. T., Sahakian, B. J. \& Robbins, T. W. (2003) Nat. Neurosci. 6, 115-116.

6. Blumberg, H. P., Leung, H. C., Skudlarski, P., Lacadie, C. M., Fredericks, C. A., Harris, B. C., Charney, D. S., Gore, J. C., Krystal, J. H. \& Peterson, B. S. (2003) Arch. Gen. Psychiatry 60, 601-609.

7. Rubia, K., Smith, A. B., Brammer, M. J. \& Taylor, E. (2003) Neuroimage 20, 351-358.

8. Elliott, R., Ogilvie, A., Rubinsztein, J. S., Calderon, G., Dolan, R. J. \& Sahakian, B. J. (2004) Biol. Psychiatry 55, 1163-1170.

9. Strakowski, S. M., Adler, C. M., Holland, S. K., Mills, N. \& DelBello, M. P. (2004) Neuropsychopharmacology 29, 1734-1740.

10. Lawrence, N. S., Williams, A. M., Surguladze, S., Giampietro, V., Brammer, M. J., Andrew, C., Frangou, S., Ecker, C. \& Phillips, M. L. (2004) Biol. Psychiatry 55, 578587.

11. Blumberg, H. P., Stern, E., Ricketts, S., Martinez, D., de Asis, J., White, T., Epstein, J., Isenberg, N., McBride, P. A., Kemperman, I. et al. (1999) Am. J Psychiatry 156, 19861988.

12. Rubinsztein, J. S., Fletcher, P. C., Rogers, R. D., Ho, L. W., Aigbirhio, F. I., Paykel, E. S., Robbins, T. W. \& Sahakian, B. J. (2001) Brain 124, 2550-2563.

13. Blumberg, H. P., Leung, H. C., Skudlarski, P., Lacadie, C. M., Fredericks, C. A., Harris, B. C., Charney, D. S., Gore, J. C., Krystal, J. H. \& Peterson, B. S. (2003) Arch. Gen. Psychiatry 60, 601-609.

14. Elliott, R., Ogilvie, A., Rubinsztein, J. S., Calderon, G., Dolan, R. J. \& Sahakian, B. J. (2004) Biol. Psychiatry 55, 1163-1170. 
15. Strakowski, S. M., Adler, C. M., Holland, S. K., Mills, N. \& DelBello, M. P. (2004) Neuropsychopharmacology 29, 1734-1740.

16. Lawrence, N. S., Williams, A. M., Surguladze, S., Giampietro, V., Brammer, M. J., Andrew, C., Frangou, S., Ecker, C. \& Phillips, M. L. (2004) Biol. Psychiatry 55, 578587.

17. Chang, K., Adleman, N. E., Dienes, K., Simeonova, D. I., Menon, V. \& Reiss, A. (2004) Arch Gen Psychiatry 61, 781-792.

18. Elliott, R., Ogilvie, A., Rubinsztein, J. S., Calderon, G., Dolan, R. J. \& Sahakian, B. J. (2004) Biol. Psychiatry 55, 1163-1170.

19. Lennox, B. R., Jacob, R., Calder, A. J., Lupson, V. \& Bullmore, E. T. (2004) Psychol. Med. 34, 795-802.

20. Oosterlaan, J., Logan, G. D. \& Sergeant, J. A. (1998) J Child Psychol. Psychiatry 39, 411-425.

21. Kaufman, J., Birmaher, B., Brent, D., Rao, U., Flynn, C., Moreci, P., Williamson, D. \& Ryan, N. (1997) J Am. Acad. Child Adolesc. Psychiatry 36, 980-988.

22. Fristad, M. A., Weller, E. B. \& Weller, R. A. (1992) J. Am. Acad. Child Adolesc. Psychiatry 31, 252-257.

23. Poznanski, E., Mokros, H. B., Grossman, J. \& Freeman, L. N. (1985) Am J Psychiatry 142, 1168-1173.

24. Kaufman, J., Birmaher, B., Brent, D., Rao, U., Flynn, C., Moreci, P., Williamson, D. \& Ryan, N. (1997) J Am. Acad. Child Adolesc. Psychiatry 36, 980-988.

25. Wechsler D. (1999) Wechsler Abbreviated Scale of Intelligence (The Psychological Corporation, San Antonio, TX).

26. Logan, G. D. (1994) J. Exp. Psychol. Hum. Percept. Perform. 20, 1015-1036.

27. Logan, G. D., Schachar, R. J. \& Tannock, R. (1997) Psychological Science 8, 60-64.

28. Williams, B. R., Ponesse, J. S., Schachar, R. J., Logan, G. D. \& Tannock, R. (1999) Dev. Psychol. 35, 205-213.

29. Szeszko, P. R., Bilder, R. M., Lencz, T., Pollack, S., Alvir, J. M., Ashtari, M., Wu, H. \& Lieberman, J. A. (1999) Psychiatry Res. 90, 1-15.

30. Peterson, B. S., Thomas, P., Kane, M. J., Scahill, L., Zhang, H., Bronen, R., King, R. A., Leckman, J. F. \& Staib, L. (2003) Arch. Gen. Psychiatry 60, 415-424.

31. Szeszko, P. R., Strous, R. D., Goldman, R. S., Ashtari, M., Knuth, K. H., Lieberman, J. A. \& Bilder, R. M. (2002) Am. J. Psychiatry 159, 217-226. 
32. Rosenberg, D. R., Mirza, Y., Russell, A., Tang, J., Smith, J. M., Banerjee, S. P., Bhandari, R., Rose, M., Ivey, J., Boyd, C. et al. (2004) J. Am. Acad. Child Adolesc. Psychiatry 43, 1146-1153.

33. Ernst M, Nelson EE, Jazbec S, McClure EB, Monk CS, Leibenluft E, Blair J \& Pine DS (2005) Neuroimage.

34. McClure, E. B., Treland, J. E., Snow, J., Schmajuk, M., Dickstein, D. P., Towbin, K. E., Charney, D. S., Pine, D. S. \& Leibenluft, E. (2004) Am. J. Psychiatry.

35. Rolls, E. T., Hornak, J., Wade, D. \& McGrath, J. (1994) J Neurol. Neurosurg. Psychiatry 57, 1518-1524.

36. Bullmore, E., Suckling, J., Zelaya, F., Long, C., Honey, G., Reed, L., Routledge, C., Ng, V., Fletcher, P., Brown, J. et al. (2003) Cereb. Cortex 13, 144-154.

37. Schultz, W. (2004) Curr. Opin. Neurobiol. 14, 139-147.

38. Blumberg, H. P., Martin, A., Kaufman, J., Leung, H. C., Skudlarski, P., Lacadie, C., Fulbright, R. K., Gore, J. C., Charney, D. S., Krystal, J. H. et al. (2003) Am. J Psychiatry 160, 1345-1347.

39. Lawrence, N. S., Williams, A. M., Surguladze, S., Giampietro, V., Brammer, M. J., Andrew, C., Frangou, S., Ecker, C. \& Phillips, M. L. (2004) Biol. Psychiatry 55, 578587.

40. Chang, K., Adleman, N. E., Dienes, K., Simeonova, D. I., Menon, V. \& Reiss, A. (2004) Arch Gen Psychiatry 61, 781-792.

41. Malhi, G. S., Lagopoulos, J., Sachdev, P., Mitchell, P. B., Ivanovski, B. \& Parker, G. B. (2004) Bipolar. Disord. 6, 271-285.

42. Blumberg, H. P., Martin, A., Kaufman, J., Leung, H. C., Skudlarski, P., Lacadie, C., Fulbright, R. K., Gore, J. C., Charney, D. S., Krystal, J. H. et al. (2003) Am. J Psychiatry 160, 1345-1347.

43. Malhi, G. S., Lagopoulos, J., Sachdev, P., Mitchell, P. B., Ivanovski, B. \& Parker, G. B. (2004) Bipolar. Disord. 6, 271-285.

44. Blumberg, H. P., Martin, A., Kaufman, J., Leung, H. C., Skudlarski, P., Lacadie, C., Fulbright, R. K., Gore, J. C., Charney, D. S., Krystal, J. H. et al. (2003) Am. J Psychiatry 160, 1345-1347.

45. Chang, K., Adleman, N. E., Dienes, K., Simeonova, D. I., Menon, V. \& Reiss, A. (2004) Arch Gen Psychiatry 61, 781-792. 
46. Lawrence, N. S., Williams, A. M., Surguladze, S., Giampietro, V., Brammer, M. J., Andrew, C., Frangou, S., Ecker, C. \& Phillips, M. L. (2004) Biol. Psychiatry 55, 578587.

47. Cassidy, F., Ahearn, E. P. \& Carroll, B. J. (2001) Bipolar. Disord. 3, 181-188.

48. Leibenluft, E., Blair, R. J., Charney, D. S. \& Pine, D. S. (2003) Ann. N. Y. Acad. Sci. 1008, 201-218.

49. Hoeksma, J. B., Oosterlaan, J. \& Schipper, E. M. (2004) Child Dev. 75, 354-360.

50. Klein, D. F. \& Stewart, J. (2004) Neurotox. Res. 6, 11-15. 
Table 1. Demographic and clinical characteristics

\begin{tabular}{|c|c|c|}
\hline Characteristic & Controls (N=17) & Bipolar (N=26) \\
\hline Gender: \% male $(\mathrm{N})$ & $53(9)$ & $46(12)$ \\
\hline Age (years; mean \pm SD) & $14.6+1.8$ & $13.6+2.6$ \\
\hline WASI FSIQ (mean \pm SD) & $109.9+12.3(\mathrm{~N}=15)$ & $106.7+13.0(\mathrm{~N}=22)$ \\
\hline Bipolar I: \% (N) & -- & 91.7 (22) (two missing) \\
\hline Bipolar II: \% (N) & -- & $8.3(2)$ \\
\hline $\begin{array}{l}\text { Young Mania Rating Score } \\
(\text { mean } \pm \text { SD) }\end{array}$ & -- & $7.3+5.5$ \\
\hline $\begin{array}{l}\text { Children’s Depression Rating Score } \\
\text { (mean } \pm \text { SD) }\end{array}$ & -- & $24.3+6.1$ \\
\hline \# Comorbid diagnoses (mean \pm SD) & -- & $1.4+1.0$ (two missing) \\
\hline Comorbid ADHD ${ }^{1}: \%(\mathrm{~N})$ & -- & $57.7(15)$ \\
\hline Comorbid anxiety disorder: \% (N) & -- & 54.2 (13) (two missing) \\
\hline Comorbid ODD/CD²: \% (N) & -- & 37.5 (9) (two missing) \\
\hline Unmedicated: \% (N) & -- & $50 \%(13)$ \\
\hline$\#$ of Medications $(\text { mean } \pm \text { SD) })^{3}$ & -- & $3.2+1.1$ \\
\hline Atypical Antipsychotic: \% (N) & -- & $84.6(11)$ \\
\hline Lithium: \% (N) & -- & $46.2(6)$ \\
\hline Anti-Epileptic Drug (AED) ${ }^{4}: \%(\mathrm{~N})$ & -- & $84.6(11)$ \\
\hline Antidepressant: \% (N) & -- & $30.8(4)$ \\
\hline Stimulant: \% (N) & -- & $30.8(4)$ \\
\hline Other: \% (N) & -- & $15.4(2)$ \\
\hline
\end{tabular}

1= Attention deficit hyperactivity disorder; $2=$ Oppositional defiant disorder or conduct disorder; $3=$ =nly children on medication are included in this analysis; $4=$ includes oxcarbamazepine, topiramate, lamotrigine, carbamazepine, sodium valproate, clonazepam 
Table 2. Performance on the stop signal task during scanning

\begin{tabular}{|l|l|l|l|l|l|}
\hline Variable (mean \pm SD) & Controls (N=17) & BPD (N=26) & t & df & p \\
\hline \% accurate go & $93.8+6.2$ & $85.8+11.3$ & 3.0 & 40.1 & .005 \\
\hline \% accurate stop & $54.0+11.9$ & $50.9+7.7$ & 0.94 & 25.6 & NS \\
\hline $\begin{array}{l}\text { Go reaction time } \\
\text { (msec) }\end{array}$ & $738.5+135.0$ & $733.6+87.4$ & 0.13 & 25.4 & NS \\
\hline Inhibit delay* (msec) & $508.7+138.1$ & $488.0+90.8$ & 0.58 & 39 & NS \\
\hline SSRT** (msec) & $229.6+\underline{+5.3}$ & $216.3+47.4$ & 0.84 & 38 & NS \\
\hline
\end{tabular}

* Inhibit delay= interval between onset of go and onset of stop signals.

** SSRT $=$ stop signal reaction time. See text for method of calculation. 
Table 3. Significant between-group activations in stop incorrect vs. go contrast in regions of interest

\begin{tabular}{|l|l|l|l|l|l|l|l|l|}
\hline GROUPS & Region & L/R & voxels & $\mathbf{x}$ & $\mathbf{y}$ & $\mathbf{z}$ & $\mathbf{t}$ & $\mathbf{p}$ \\
\hline C vs. All BPD & accumbens & $\mathrm{L}$ & 117 & -10 & 14 & -2 & 4.05 & .001 \\
\hline & caudate & $\mathrm{L}$ & 395 & -10 & 12 & 0 & 4.22 & .002 \\
\hline & putamen & $\mathrm{L}$ & 250 & -14 & 16 & 2 & 3.74 & .008 \\
\hline & vPFC & $\mathrm{R}$ & 312 & 32 & 28 & -6 & 3.24 & .034 \\
\hline & accumbens & $\mathrm{R}$ & 131 & 12 & 14 & -8 & 3.54 & .005 \\
\hline & caudate & $\mathrm{R}$ & 468 & 12 & 12 & 0 & 3.03 & .041 \\
\hline & putamen & $\mathrm{R}$ & 270 & 18 & 16 & -6 & 3.23 & .027 \\
\hline & & & & & & & & \\
\hline & accumbens & $\mathrm{L}$ & 127 & -10 & 14 & -2 & 4.09 & .001 \\
\hline C vs. unmed BPD & caudate & $\mathrm{L}$ & 463 & -10 & 12 & 0 & 4.21 & .002 \\
\hline & putamen & $\mathrm{L}$ & 328 & -14 & 16 & 2 & 4.15 & .003 \\
\hline & vPFC & $\mathrm{R}$ & 190 & 22 & 22 & -10 & 2.96 & .061 \\
\hline & accumbens & $\mathrm{R}$ & 145 & 12 & 14 & -8 & 3.89 & .002 \\
\hline & caudate & $\mathrm{R}$ & 645 & 18 & 18 & -4 & 3.25 & .001 \\
\hline & putamen & $\mathrm{R}$ & 285 & 18 & 14 & -8 & 3.66 & .010 \\
\hline & & & & & & & & \\
\hline & accumbens & $\mathrm{L}$ & 77 & -8 & 14 & -2 & 2.97 & .021 \\
\hline & caudate & $\mathrm{L}$ & 129 & -10 & 12 & 0 & 3.06 & .034 \\
\hline C vs. med BPD & vPFC & $\mathrm{R}$ & 355 & 34 & 26 & -8 & 3.37 & .026 \\
\hline & accumbens & $\mathrm{R}$ & 77 & 10 & 14 & -6 & 2.45 & .057 \\
\hline & & & & & & & & \\
\hline & vPFC & $\mathrm{L}$ & 232 & -34 & 24 & 0 & 3.24 & .040 \\
\hline & ant cingulate & $\mathrm{L}$ & 800 & 4 & 40 & 12 & 3.58 & .027 \\
\hline C vs. BPD+ADHD & accumbens & $\mathrm{L}$ & 96 & -10 & 14 & -2 & 3.67 & .004 \\
\hline & putamen & $\mathrm{L}$ & 343 & -14 & 14 & 2 & 3.60 & .011 \\
\hline & vPFC & $\mathrm{R}$ & 354 & 34 & 32 & -6 & 3.75 & .011 \\
\hline & ant cingulate & $\mathrm{R}$ & 1167 & 8 & 40 & 12 & 3.73 & .016 \\
\hline & accumbens & $\mathrm{R}$ & 123 & 12 & 12 & -4 & 3.29 & .009 \\
\hline & caudate & $\mathrm{R}$ & 562 & 12 & 12 & 0 & 3.05 & .039 \\
\hline & putamen & $\mathrm{R}$ & 395 & 28 & 18 & 6 & 3.34 & .021 \\
\hline & & & & & & & & \\
\hline & accumbens & $\mathrm{L}$ & 112 & -8 & 14 & 0 & 3.30 & .010 \\
\hline & caudate & $\mathrm{L}$ & 206 & -8 & 12 & 0 & 3.44 & .014 \\
\hline & putamen & $\mathrm{L}$ & 92 & -14 & 16 & 2 & 2.83 & .062 \\
\hline & accumbens & $\mathrm{R}$ & 114 & 12 & 14 & -8 & 2.80 & .028 \\
\hline & & & & & & &
\end{tabular}

ant cingulate $=$ anterior cingulate; $\mathrm{vPFC}=$ ventral prefrontal cortex; $\mathrm{C}=$ controls; $\mathrm{BPD}=$ patients with bipolar disorder; med=medicated; unmed=unmedicated; BPD+ADHD=patients with BPD and ADHD; BPD-ADHD=patients with BPD, without ADHD Coordinates are in MNI space. Significance is defined as $\mathrm{p}<.05$ on a small volume corrected, region of interest analysis.

Note: Many areas of activation had multiple significant maxima within the cluster noted. In the interest of space, only the maximum with the highest $t$ value is reported for each cluster. 
Table 4. Significant between-group activations in stop correct vs. stop incorrect contrast in regions of interest

\begin{tabular}{|l|l|l|l|l|l|l|l|l|}
\hline GROUPS & Region & L/R & voxels & $\mathbf{x}$ & $\mathbf{y}$ & $\mathbf{z}$ & $\mathbf{t}$ & $\mathbf{p}$ \\
\hline All BPD vs. C & vPFC & $\mathrm{R}$ & 335 & 34 & 26 & -6 & 3.30 & .032 \\
\hline & & & & & & & & \\
\hline Unmed BPD vs. C & accumbens & $\mathrm{L}$ & 65 & -14 & 4 & -6 & 2.60 & .048 \\
\hline & caudate & $\mathrm{L}$ & 294 & -10 & 10 & 8 & 3.02 & .038 \\
\hline & putamen & $\mathrm{L}$ & 474 & -14 & 10 & 2 & 3.13 & .035 \\
\hline & vPFC & $\mathrm{R}$ & 417 & 34 & 24 & -6 & 4.04 & .006 \\
\hline & ant cingulate & $\mathrm{R}$ & 507 & 10 & 14 & 26 & 3.26 & .048 \\
\hline & accumbens & $\mathrm{R}$ & 145 & 16 & 16 & -8 & 3.03 & .017 \\
\hline & caudate & $\mathrm{R}$ & 551 & 12 & 12 & 20 & 3.26 & .026 \\
\hline & putamen & $\mathrm{R}$ & 445 & 26 & 18 & -6 & 3.11 & .036 \\
\hline & & & & & & & & \\
\hline & accumbens & $\mathrm{L}$ & 36 & -14 & 4 & -12 & 2.79 & .033 \\
\hline Unmed BPD vs. med BPD & putamen & $\mathrm{L}$ & 661 & -26 & 10 & 4 & 3.04 & .042 \\
\hline & ant cingulate & $\mathrm{R}$ & 179 & 10 & 14 & 26 & 3.46 & .031 \\
\hline & accumbens & $\mathrm{R}$ & 108 & 10 & 4 & -6 & 2.67 & .038 \\
\hline & caudate & $\mathrm{R}$ & 357 & 14 & 12 & 22 & 3.70 & .009 \\
\hline & & & & & & & & \\
\hline & vPFC & $\mathrm{R}$ & 412 & 34 & 26 & -6 & 3.78 & .010 \\
\hline BPD+ADHD vs. C & putamen & $\mathrm{R}$ & 283 & 30 & 18 & 4 & 3.01 & .045 \\
\hline & & & & & & & & \\
\hline & vPFC & $\mathrm{L}$ & 106 & -24 & 20 & -2 & 3.12 & .053 \\
\hline BPD+ADHD vs. \\
BPD-ADHD & & & & & & & & \\
\hline & accumbens & $\mathrm{L}$ & 106 & -14 & 4 & -6 & 3.35 & .009 \\
\hline & caudate & $\mathrm{L}$ & 65 & -12 & 16 & -2 & 2.94 & .044 \\
\hline & putamen & $\mathrm{L}$ & 740 & -16 & 10 & -4 & 3.61 & .011 \\
\hline & vPFC & $\mathrm{R}$ & 362 & 30 & 22 & -6 & 3.07 & .050 \\
\hline & accumbens & $\mathrm{R}$ & 111 & 14 & 12 & -12 & 3.20 & .011 \\
\hline & putamen & $\mathrm{R}$ & 790 & 34 & -8 & 2 & 4.12 & .003 \\
\hline
\end{tabular}

ant cingulate $=$ anterior cingulate; $\mathrm{vPFC}=$ ventral prefrontal cortex; $\mathrm{C}=$ controls; $\mathrm{BPD}=$ patients with bipolar disorder; med=medicated; unmed=unmedicated; BPD+ADHD=patients with BPD and ADHD; BPD-ADHD=patients with BPD, without ADHD

Coordinates are in MNI space. Significance is defined as $\mathrm{p}<.05$ on a small volume corrected, region of interest analysis.

Note: Many areas of activation had multiple significant maxima within the cluster noted. In the interest of space, only the maximum with the highest $t$ value is reported for each cluster. 
Fig. 1a. Activation on stop incorrect vs. go contrast, controls vs. all bipolar patients. Data shown at $\mathrm{p}<.005$, whole brain uncorrected, for purposes of presentation. Peak activation in left caudate, $\mathrm{x}=-10, \mathrm{y}=12, \mathrm{z}=0, \mathrm{t}=4.22, \mathrm{k}_{\mathrm{E}}=395, \mathrm{p}=.002$.
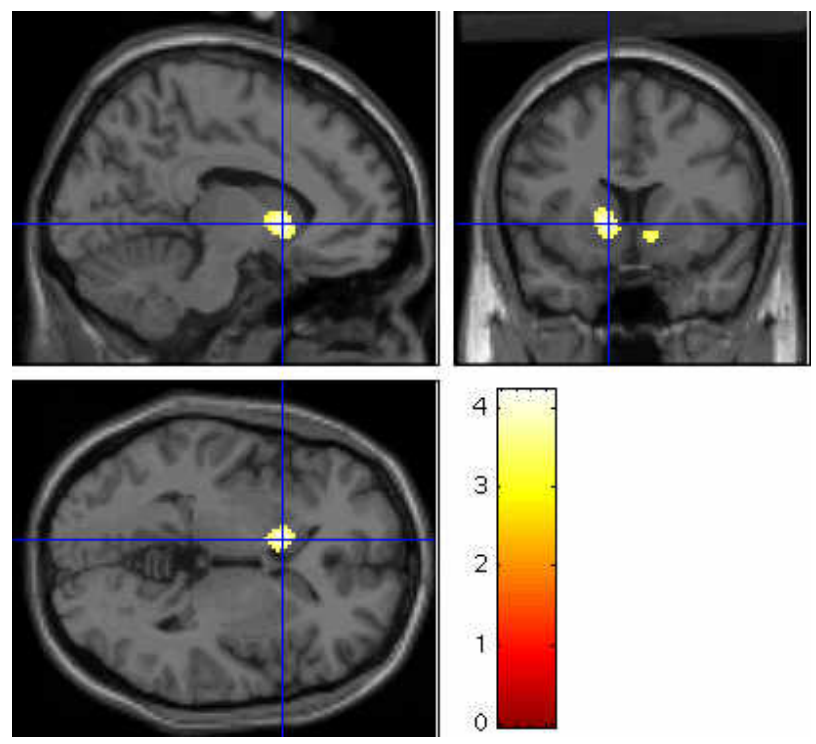

Fig. 1b. Activation at -10, 12, 0 in controls and all bipolar patients on the stop correct vs. fixation, stop incorrect vs. fixation, and go correct vs. fixation contrasts.

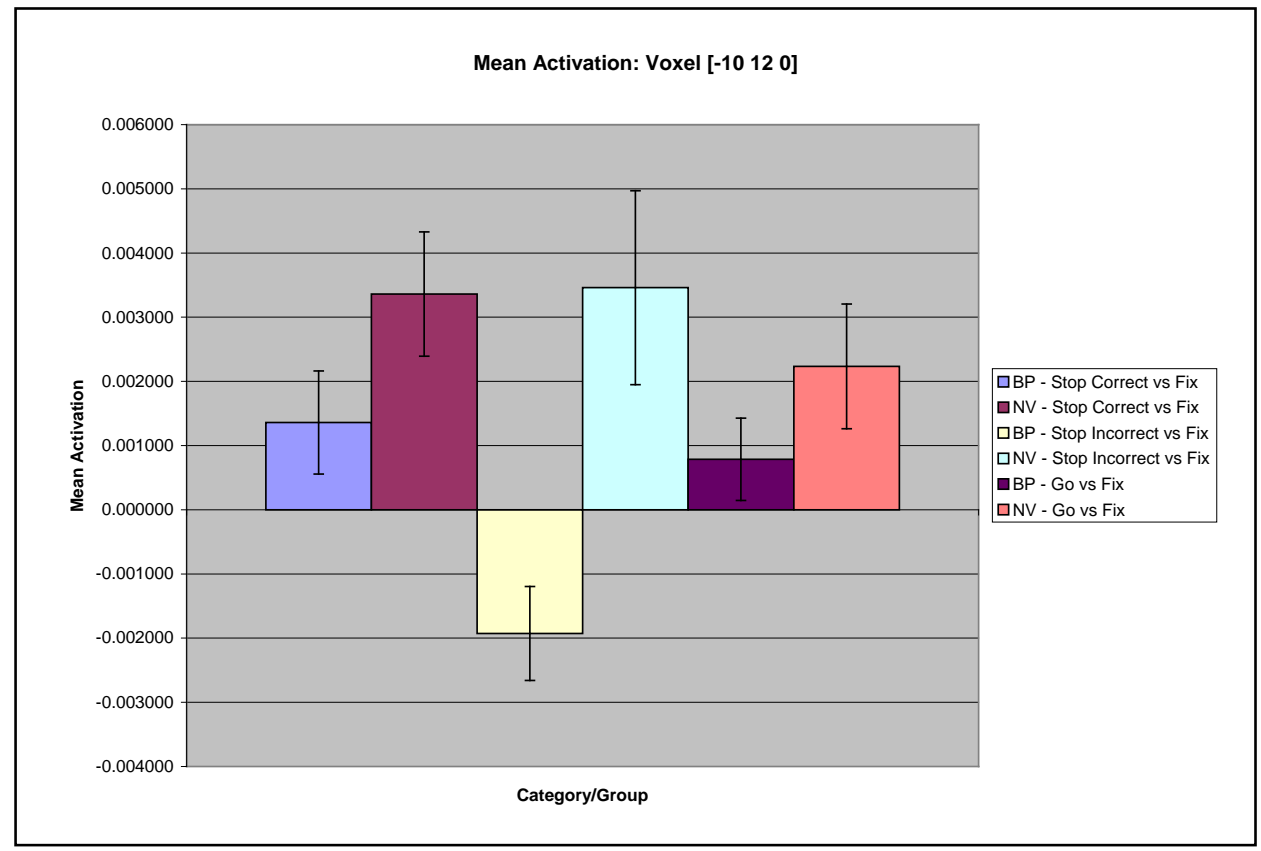

